\title{
Risk factors, quality of care and prognosis in South Asian, East Asian and White patients with stroke
}

\author{
Nadia A Khan ${ }^{1 *}$, Hude Quan², Michael D Hill ${ }^{2,3}$, Louise Pilote ${ }^{4}$, Finlay A McAlister ${ }^{5}$, Anita Palepu', Baiju R Shah ${ }^{6,7}$, \\ Limei Zhou', Hong Zhen ${ }^{7}$ and Moira K Kapral ${ }^{6,7}$
}

\begin{abstract}
Background: Stroke has emerged as a significant and escalating health problem for Asian populations. We compared risk factors, quality of care and risk of death or recurrent stroke in South Asian, East Asian and White patients with acute ischemic and hemorrhagic stroke.

Methods: Retrospective analysis was performed on consecutive patients with ischemic stroke or intracerebral hemorrhage admitted to 12 stroke centers in Ontario, Canada (July 2003-March 2008) and included in the Registry of the Canadian Stroke Network database. The database was linked to population-based administrative databases to determine one-year risk of death or recurrent stroke.

Results: The study included 253 South Asian, 513 East Asian and 8231 White patients. East Asian patients were more likely to present with intracerebral hemorrhage (30\%) compared to South Asian (17\%) or White patients (15\%) $(p<0.001)$. Time from stroke to hospital arrival was similarly poor with delays $>2$ hours for more than two thirds of patients in all ethnic groups. Processes of stroke care, including thrombolysis, diagnostic imaging, antithrombotic medications, and rehabilitation services were similar among ethnic groups. Risk of death or recurrent stroke at one year after ischemic stroke was similar for patients who were White (27.6\%), East Asian (24.7\%, aHR 0.97, 95\% Cl 0.78-1.21 vs. White), or South Asian (21.9\%, aHR 0.91, 95\% Cl 0.67-1.24 vs. White). Although risk of death or recurrent stroke at one year after intracerebral hemorrhage was higher in East Asian (35.5\%) and White patients (47.9\%) compared to South Asian patients (30.2\%) ( $\mathrm{p}=0.002)$, these differences disappeared after adjustment for age, sex, stroke severity and comorbid conditions (aHR 0.89 [0.67-1.19] for East Asian vs White and 0.99 [0.54-1.81] for South Asian vs. White).
\end{abstract}

Conclusion: After stratification by stroke type, stroke care and outcomes are similar across ethnic groups in Ontario. Enhanced health promotion is needed to reduce delays to hospital for all ethnic groups.

\section{Background}

There is an emerging epidemic of acute stroke in Asian populations, with recent data suggesting that the prevalence of stroke has increased 3 to 5 fold in the last 40 years in South Asian patients [1] whereas stroke rates have plateaued or declined in general North American populations [2]. The Sino-MONICA-Beijing stroke study also reported a higher incidence of stroke, particularly hemorrhagic stroke, in China compared to other

\footnotetext{
* Correspondence: nakhanubc@gmail.com

'Department of Medicine, University of British Columbia, 620 B, 1081 Burrard Street, St. Paul's Hospita, Vancouver, BC V6Z 1Y6, Canada

Full list of author information is available at the end of the article
}

countries [3]. Deaths due to stroke are higher in South Asian and East Asian groups compared with White patients in the UK and Canada $[4,5]$. Thus, there is a need to better understand ethnic differences in stroke, especially since South Asian and East Asian groups are among the fastest growing populations in the world [6].

Most studies have identified a strikingly higher prevalence of diabetes, hyperlipidemia, and hypertension in Asian populations with stroke compared to Whites, possibly accounting for the increased burden of stroke in Asian populations [1,7-11]. Although there is growing evidence of inter-ethnic differences in risk factors for developing stroke, there are sparse data on potential ethnic 
differences in stroke characteristics, quality of stroke care or outcomes. Existing evidence is further limited by incomplete ascertainment of risk factors, stroke and stroke type, and by studies derived from single centers and/or lacking direct comparisons between ethnic groups $[1,7,8,11-13]$. The aim of this study was to compare stroke characteristics, delivery of acute stroke care and risk of death or hospitalization for recurrent stroke in South Asian (those originating from India, or Pakistan), East Asian (originating from China, Japan, Korea, Vietnam, Thailand or Laos) and White patients with acute ischemic or intracerebral hemorrhagic stroke, using a large clinical database of patients from in 12 stroke centers in Ontario, Canada.

\section{Methods}

\section{Data sources}

We conducted a retrospective analysis of clinical data from the Registry of the Canadian Stroke Network (RCSN) from July 2003 to March 2008 in Ontario, Canada. The RCSN collects data from 12 stroke centers representing different geographic regions within the province of Ontario, Canada. Ontario has a population of 11.5 million people and contains $63 \%$ of persons of South Asian descent $(794,000)$, and $47 \%$ of persons of East Asian descent $(686,000)$ residing in Canada [6]. The registry prospectively identifies all consecutive patients with a diagnosis of acute stroke or transient ischemic attack seen in the emergency department or admitted to hospital [14]. Trained neurology research nurses collect data at each site using chart abstraction and care provider interview when needed. Detailed clinical data are collected, including demographics, stroke type, severity, clinical presentation including the Oxfordshire Community Stroke Project classification scheme for ischemic stroke [15], time intervals between stroke onset and the arrival to hospital, brain imaging, in-hospital treatment, medication prescriptions, in-hospital investigations, and discharge status. Inter-rater reliability of chart abstraction for key variables in 120 patients was substantial to excellent (kappa 0.66-1.0) [14].

The RCSN database is housed at the Institute for Clinical Evaluative Sciences, where it is linked to population-based administrative databases using unique encrypted patient identifiers. We used the Ontario Registered Persons Database to determine one-year mortality after stroke, and used the Canadian Institute for Health Information Discharge Abstract Database to identify readmissions for stroke. The Registered Persons Data Base is updated daily and includes all out of hospital deaths regardless of location within the province. The Discharge Abstract Database contains up to 16 diagnosis fields for all patients admitted to Ontario hospitals and uses the coding system of the International Classification of Diseases, $10^{\text {th }}$ revision. We used ICD-10 codes I61-I62, I63.3-I63.5, I63.8, I63.9, I64 with a positive predictive value of $0.85-0.98$ to identify recurrent hospitalization for stroke [16].

\section{Patient population}

We identified all patients aged 20 years or older with a diagnosis of acute ischemic stroke or acute intracerebral hemorrhage $(\mathrm{ICH})$. Ascertainment of stroke cases in the RCSN is based on clinical presentation and findings on computed tomography (CT) or magnetic resonance imaging (MRI) of the brain. Patients with undetermined stroke type, in-hospital or recurrent strokes were excluded.

Patients were included in the study if their ethnicity was specified as East Asian (originating from China, Japan, Korea, Vietnam, Thailand or Laos), South Asian (originating from Pakistan or India) or White. Ethnicity was determined by research nurses from chart review using recorded ethnicity (and not from interpretation of surnames) and in some cases, interviews with the care providers using the above a priori ethnic categories. Patients of other ethnic categories including Hispanic, Filipino, Black and Native Indian (3\% of total), were not included because of small sample sizes. Patients with mixed race were classified as 'other'. To maintain a high specificity of the ethnic categories, any individual without an ethnic categorization (40\% of registry patients) were not included in the analysis.

\section{Study variables}

Prognostic characteristics at baseline for this analysis included clinical variables from the Charlson Comorbidity index (previous history of myocardial infarction, heart failure, cerebrovascular disease, peripheral arterial disease, renal impairment, cancer, dementia, chronic pulmonary disease, hypertension, rheumatic disease, peptic ulcer disease, liver disease, hemiplegia, metastatic carcinoma and AIDS/HIV), atrial fibrillation, and smoking that have been shown to be predictive of mortality or recurrent stroke in patients with stroke [17-20]. Initial stroke severity was assessed using the validated Canadian Neurological Scale (CNS) [21]. Lower CNS scores correspond to greater stroke severity. Patients were recorded as "unconscious" when the clinical notes indicated that they were unresponsive or in coma at presentation. We also examined socioeconomic status (SES) using area level median household income, based on residential postal code and the 2001 Canadian Census.

Quality of care measures included the following processes of stroke care delivery: rates of thrombolysis, stroke unit admission, stroke team assessment (a multidisciplinary group of stroke specialists including physicians, nurses, occupational therapists, physiotherapists, and speech language pathologists), carotid imaging, echocardiography, and use of antithrombotic therapy. 


\section{Statistical analysis}

Baseline characteristics, processes of care, and clinical outcomes were stratified by stroke type and compared across ethnic groups using Chi-square testing or ANOVA where appropriate. To determine the independent association of ethnicity on time to death or recurrent stroke at one year, we first stratified by stroke type (ischemic or $\mathrm{ICH}$ ) then risk adjusted for prognostic covariates (age, sex, SES, Charlson comorbidity index score, CNS score, history of atrial fibrillation, smoking status, and admission to stroke unit) using Cox proportional hazards models. Secondary analyses evaluated the outcomes of death at 30 days and one year and rates of discharge home after the acute stroke admission. Analysis of deviance residuals was used to test for possible violations of the proportional hazards assumption for all Cox models. Assumptions for logistic regression modeling were met. P-values were 2 sided. Statistical significance was defined with a criterion of $\mathrm{p}<0.05$. All analyses were performed with SAS statistical software version 9.1 (SAS Institute Inc., Cary, NC). The institutional ethics review board of Sunnybrook Health Sciences Centre and the publications committee of the Registry of the Canadian Stroke Network approved this study.

\section{Results}

After exclusions (720 in-hospital strokes, 925 recurrent strokes, 439 undetermined stroke), 8,997 patients were identified with first acute stroke, with 253 categorized as South Asian, 513 as East Asian and 8231 as White. Ischemic stroke was more common than $\mathrm{ICH}$ for all ethnic groups, occurring in 70\% of East Asian, 83\% of South Asian and $85 \%$ of White patients. East Asian patients were more likely to present with ICH (29.6\%) compared to South Asian (17\%) or White patients $(14.7 \%)(\mathrm{p}<0.001)$.

\section{Risk factors and stroke characteristics}

In the cohort with $\mathrm{ICH}$, South Asian patients were younger and more likely to be male, to reside in a low income neighborhood and to have hyperlipidemia compared to White or East Asian patients, while White patients were more likely to smoke cigarettes, consume more than two alcoholic drinks per day and have a Charlson comorbidity index score of greater than two (Table 1). There was no significant difference in baseline blood pressure or prevalence of hypertension among ethnic groups. However, East Asian patients had the lowest median CNS score indicating greater stroke severity compared to South Asian or White patients.

In the cohort with ischemic stroke, South Asian patients again had a lower mean age and were more likely to be male, have hypertension, diabetes and dyslipidemia compared to other ethnic groups, while White patients were more likely to live alone, smoke cigarettes, have
Table 1 Baseline characteristics according to ethnicity for patients with $\mathrm{ICH}, \%$

\begin{tabular}{|c|c|c|c|c|}
\hline Characteristic & $\begin{array}{l}\text { East Asian } \\
\mathrm{N}=152\end{array}$ & $\begin{array}{l}\text { South Asian } \\
\mathrm{N}=43\end{array}$ & $\begin{array}{l}\text { White } \\
\mathrm{N}=1214\end{array}$ & $p$ value \\
\hline Age, mean (SD) y & $62.0(17.6)$ & $54.1(15.1)$ & $64.2(15.8)$ & $<0.001$ \\
\hline Female & 49.8 & 41.9 & 53.5 & 0.09 \\
\hline Married & 60.5 & 73.0 & 59.3 & $<0.001$ \\
\hline Living alone & 6.9 & $<5 \%$ & 16.1 & $<0.001$ \\
\hline \multicolumn{5}{|l|}{ Median income quintile } \\
\hline Q1 (low income) & 27.7 & 33.8 & 20.8 & $<0.001$ \\
\hline Q2 & 31.3 & 21.6 & 20.5 & \\
\hline Q3 & 23.2 & 18.9 & 19.3 & \\
\hline Q4 & 18.0 & 13.5 & 18.2 & \\
\hline Q5 (high income) & 11.2 & 8.1 & 20.4 & \\
\hline Previously independent & 51.5 & 56.8 & 47.1 & 0.02 \\
\hline Smoker (current) & 6.9 & $<5$ & 14.4 & 0.001 \\
\hline Alcohol (>2 drinks/day) & $<5$ & $<5$ & 3.9 & 0.008 \\
\hline Diabetes mellitus & 14.6 & 14.9 & 10.0 & 0.04 \\
\hline Hypertension & 37.8 & 32.4 & 35.2 & 0.62 \\
\hline Hyperlipidemia & 10.3 & 20.3 & 14.3 & 0.08 \\
\hline Family history of stroke & 4.7 & $<5$ & 2.7 & 0.2 \\
\hline Previous stroke or TIA & 11.2 & $<5$ & 11.2 & 0.33 \\
\hline Charlson score (>2) & 16.9 & 13.6 & 24.4 & $<0.001$ \\
\hline $\begin{array}{l}\text { Systolic blood pressure } \\
\text { mean, (SD), mmHg }\end{array}$ & $168.3(37.7)$ & $170.5(43)$ & $172.2(36)$ & 0.6 \\
\hline $\begin{array}{l}\text { Diastolic blood pressure } \\
\text { mean, (SD), mmHg }\end{array}$ & $92.7(20.9)$ & $91.8(23.5)$ & $90.1(21.6)$ & 0.2 \\
\hline \multicolumn{5}{|l|}{ LOC on arrival } \\
\hline Alert & 44.7 & 58.1 & 55.2 & 0.09 \\
\hline Drowsy & 29.6 & 27.9 & 25.5 & \\
\hline Unconscious & 23.7 & 14.0 & 18.8 & \\
\hline CNS score (median) & 5.0 & 8.0 & 6.5 & 0.005 \\
\hline CNS score $>8$ & 33.5 & 48.0 & 41.6 & 0.08 \\
\hline
\end{tabular}

Abbreviations: TIA transient ischemic attack, LOC level of consciousness, CNS Canadian Neurologic Scale.

atrial fibrillation and higher Charlson comorbidity scores (Table 2). Blood pressure on admission was higher in South Asian patients than in White or East Asian patients. Severity of stroke was slightly greater in South Asian and East Asian patients compared to White patients. There were differences in stroke presentation, with East Asian patients more likely to present with lacunar syndromes and total anterior circulation syndromes and less likely to present with TIA compared to other ethnic groups.

\section{Processes of stroke care}

Time from symptom onset to hospital arrival was delayed in all ethnic groups with nearly half of all patients 
Table 2 Baseline characteristics for patients with ischemic stroke, \%

\begin{tabular}{|c|c|c|c|c|}
\hline Characteristic & $\begin{array}{c}\text { East } \\
\text { Asian } \\
\mathrm{N}=361\end{array}$ & $\begin{array}{c}\text { South } \\
\text { Asian } \\
\mathrm{N}=210\end{array}$ & $\begin{array}{l}\text { White } \\
N=7017\end{array}$ & $p$ value \\
\hline Age, mean (SD) y & $72.0(14.4)$ & $69.1(12.8)$ & $72.3(13.7)$ & $<0.001$ \\
\hline Female & 51.0 & 40.5 & 47.8 & 0.051 \\
\hline Married & 61.2 & 62.9 & 52.8 & $<0.001$ \\
\hline Living alone & 6.9 & 8.1 & 22.8 & $<0.001$ \\
\hline \multicolumn{5}{|l|}{ Median income quintile } \\
\hline Q1 (low income) & 26.0 & 31.4 & 21.4 & $<0.001$ \\
\hline Q2 & 23.3 & 21.4 & 21.3 & \\
\hline Q3 & 17.2 & 19.5 & 18.2 & \\
\hline Q4 & 16.3 & 13.8 & 17.9 & \\
\hline Q5 (high income) & 16.1 & 12.4 & 19.7 & \\
\hline Previously independent & 77.0 & 76.2 & 80.0 & 0.2 \\
\hline Smoker (current) & 12.5 & 8.1 & 19.5 & $<0.001$ \\
\hline Alcohol (>2 drinks/day) & 1.9 & $<5$ & 6.2 & $<0.001$ \\
\hline Diabetes mellitus & 26.3 & 41.9 & 24.5 & $<0.001$ \\
\hline Hypertension & 72.0 & 74.8 & 67.8 & 0.03 \\
\hline Dyslipidemia & 30.7 & 42.4 & 34.4 & 0.02 \\
\hline Family history of stroke & 7.8 & 9.5 & 9.6 & 0.5 \\
\hline Peripheral arterial disease & 2.5 & 4.3 & 6.9 & 0.002 \\
\hline Atrial fibrillation & 13.3 & 9.0 & 17.4 & $<0.001$ \\
\hline $\begin{array}{l}\text { Previous myocardial } \\
\text { Infarction }\end{array}$ & 6.6 & 15.7 & 15.0 & $<0.001$ \\
\hline Previous stroke or TIA & 28.8 & 30.5 & 32.0 & 0.4 \\
\hline Charlson score $(>2)$ & 19.9 & 30.5 & 36.8 & $<0.001$ \\
\hline $\begin{array}{l}\text { Systolic blood pressure } \\
\text { mean, (SD), mmHg }\end{array}$ & $158.1(29.7)$ & $164(32.3)$ & $159.1(30)$ & 0.04 \\
\hline $\begin{array}{l}\text { Diastolic blood pressure } \\
\text { mean, (SD), mmHg }\end{array}$ & $83.8(16)$ & $84.6(16.8)$ & $83(17)$ & 0.049 \\
\hline \multicolumn{5}{|l|}{ LOC on arrival } \\
\hline Alert & 79.8 & 85.7 & 87.8 & $<0.001$ \\
\hline Drowsy & 16.3 & 10.5 & 9.7 & \\
\hline Unconscious & 2.8 & 2.9 & 2.2 & \\
\hline CNS score (median) & 8.5 & 8.5 & 9 & $<0.001$ \\
\hline CNS score $>8$ & 53.3 & 57.0 & 58.7 & 0.1 \\
\hline \multicolumn{5}{|l|}{$\begin{array}{l}\text { Oxford Community Stroke } \\
\text { Project }\end{array}$} \\
\hline Lacunar syndrome & 23.9 & 18.6 & 16.1 & 0.01 \\
\hline Partial anterior & 35.2 & 40.2 & 39.3 & \\
\hline Posterior circulation & 20.6 & 20.1 & 23.2 & \\
\hline Total anterior circulation & 13 & 9.3 & 11.0 & \\
\hline TIA & 5.4 & 7.8 & 6.0 & \\
\hline
\end{tabular}

Abbreviations: TIA transient ischemic attack, LOC level of consciousness, CNS Canadian Neurologic Scale. arriving more than 6 hours after stroke symptom onset (Table 3). Among those admitted to hospital (85\% of East Asian, $79.4 \%$ of South Asian and $85 \%$ of White patients), East Asian patients were more often admitted to the ICU. However, this difference was not evident when stroke types were examined individually. Use of CT scan, carotid imaging, echocardiography, prescribing of antithrombotic medications, and referral to rehabilitation services were similar between the groups. Among patients with ischemic stroke arriving within 2 hours of symptom onset, East Asian and South Asian patients were more likely than White patients to receive thrombolytic therapy.

\section{Prognosis}

By one year, $43.9 \%$ of patients with $\mathrm{ICH}$ and $22.2 \%$ of patients with ischemic stroke had died. In the cohort with $\mathrm{ICH}$, both one-year mortality and the combined endpoint of one-year mortality or recurrent stroke admission were lower in South Asian and East Asian patients compared to White patients (Table 4, Figure 1). However, this was no longer significant after adjustment for baseline differences (Table 5). In the cohort with ischemic stroke,

Table 3 Emergency department and hospital processes of care for ischemic stroke and ICH, \%

\begin{tabular}{|c|c|c|c|c|}
\hline Characteristic & $\begin{array}{l}\text { East Asian } \\
\quad \mathrm{N}=513\end{array}$ & $\begin{array}{l}\text { South Asian } \\
\mathrm{N}=253\end{array}$ & $\begin{array}{l}\text { White } \\
\mathrm{N}=8231\end{array}$ & $p$ value \\
\hline \multicolumn{5}{|l|}{ Time to arrival to ER } \\
\hline Median time (h) & 5.97 & 4.9 & 5.1 & 0.3 \\
\hline$>6$ hours & 49.9 & 47.0 & 47.3 & 0.09 \\
\hline 2-6 hours & 20.1 & 23.7 & 18.7 & \\
\hline$<2$ hours & 30.0 & 29.3 & 34.0 & \\
\hline$C T$ scan & 99.4 & 99.2 & 99.3 & 0.9 \\
\hline \multicolumn{5}{|l|}{ Admission to } \\
\hline Stroke unit & 42.2 & 53.7 & 51.2 & $<0.001$ \\
\hline ICU & 14.9 & 11.9 & 11 & \\
\hline Stroke team consult & 77.8 & 82.6 & 78 & 0.3 \\
\hline Neurosurgery consult & 84.6 & 88.1 & 84.1 & 0.3 \\
\hline Occupational therapy & 77.5 & 77.6 & 78.2 & 0.9 \\
\hline Physiotherapy & 81.4 & 81.6 & 82.1 & 0.9 \\
\hline Speech therapy & 64.9 & 62.7 & 61.1 & 0.3 \\
\hline \multicolumn{5}{|l|}{ Ischemic stroke } \\
\hline $\begin{array}{l}\text { tPA in those presenting } \\
\text { within } 2 \mathrm{hrs}\end{array}$ & 48.5 & 44.8 & 36 & 0.02 \\
\hline Carotid imaging & 78.7 & 77.6 & 79.4 & 0.8 \\
\hline Echocardiography & 67 & 69 & 71.2 & 0.2 \\
\hline $\mathrm{ASA}^{*}$ & 92 & 90.9 & 92.5 & 0.7 \\
\hline $\begin{array}{l}\text { Warfarin for atrial } \\
\text { fibrillation* }\end{array}$ & 64.4 & 65.4 & 69.4 & 0.7 \\
\hline
\end{tabular}

*Among those alive at discharge. 
Table 4 Unadjusted outcomes according to ethnicity

\begin{tabular}{lcccc}
\hline Outcomes & $\begin{array}{c}\text { East } \\
\text { Asian }\end{array}$ & $\begin{array}{c}\text { South } \\
\text { Asian }\end{array}$ & White & p value \\
\hline Intracerebral hemorrhage & $\mathrm{N}=152$ & $\mathrm{~N}=43$ & $\mathrm{~N}=1214$ & \\
Discharged home* \% & 27.8 & 45.5 & 28.5 & 0.1 \\
Mortality at 30 days \% & 32.9 & 27.9 & 35.4 & 0.5 \\
Mortality at one year \% & 35.5 & 30.2 & 45.4 & 0.01 \\
Mortality or recurrent stroke & 35.5 & 30.2 & 47.9 & 0.002 \\
at one year \% & & & & \\
Ischemic stroke & $\mathrm{N}=361$ & $\mathrm{~N}=210$ & $\mathrm{~N}=7017$ & \\
Discharged home* \% & 43.1 & 52.8 & 49.7 & 0.04 \\
Mortality at 30days \% & 10.2 & 9.5 & 12.0 & 0.3 \\
Mortality at one year \% & 19.9 & 19.0 & 22.4 & 0.3 \\
Mortality or recurrent stroke & 24.7 & 21.9 & 27.6 & 0.1 \\
at one year \% & & & & \\
\hline
\end{tabular}

${ }^{*}$ Among those alive at discharge.

East Asian patients were less likely than White patients to be discharged home (adjusted HR 0.70; 95\% CI 0.54 to 0.90), however, there were no significant differences in 30-day mortality, 1-year mortality or risk of death or recurrent stroke among ethnic groups (Figure 2, Tables 4 and 5).

\section{Discussion}

In this large cohort of stroke patients with detailed socio-demographic and clinical information, we found substantial differences in risk factors and stroke characteristics among those identified as East Asian, South Asian and White ethnic groups. However, processes of stroke care delivery and stroke outcomes were similar among ethnic groups.

Our finding of more frequent and more severe $\mathrm{ICH}$ in East Asian patients compared to White or South Asian patients is consistent with previous studies [11-13,22]. It has been speculated that higher rates of hemorrhagic stroke in East Asian patients is related to a greater prevalence of hypertension and a greater propensity to experience hemorrhagic stroke at lower systolic blood pressure levels than other Western populations [23,24]. In our study, both a pre-stroke history of hypertension and baseline systolic blood pressure on presentation were similar among ethnic groups, while alcohol intake another potential risk factor for hemorrhagic stroke - was lower in East Asian compared to other ethnic groups. South Asian patients with ICH were 10 years younger on average compared to White or East Asian patients, but tended to have strokes of lesser severity than those seen in White or East Asian patients. This younger age at presentation with ICH in the South Asian patients is consistent with other stroke studies [7,25]. Our study found that baseline risk factors that could be associated with premature strokes, such as hypertension, dyslipidemia and diabetes, were more common in South Asian compared to other ethnic groups. However, other risk factors for ICH were paradoxically favorable in South Asian patients -fewer comorbid conditions overall, less smoking, and lower alcohol intake.

In our cohort with ischemic stroke, we also found that South Asian patients had a significantly higher prevalence of diabetes, dyslipidemia, and hypertension compared with other ethnic groups. This constellation of disproportionately elevated vascular risk factors is consistent with other studies of heart disease and ischemic stroke in South Asian populations [7-10,25-27]. Our findings of a higher prevalence of atrial fibrillation, alcohol consumption, and tobacco use in White patients with ischemic stroke are also consistent with other reports [1,7].

Ensuring a high standard of pre-hospital and hospital stroke care regardless of ethnicity is a critical goal for

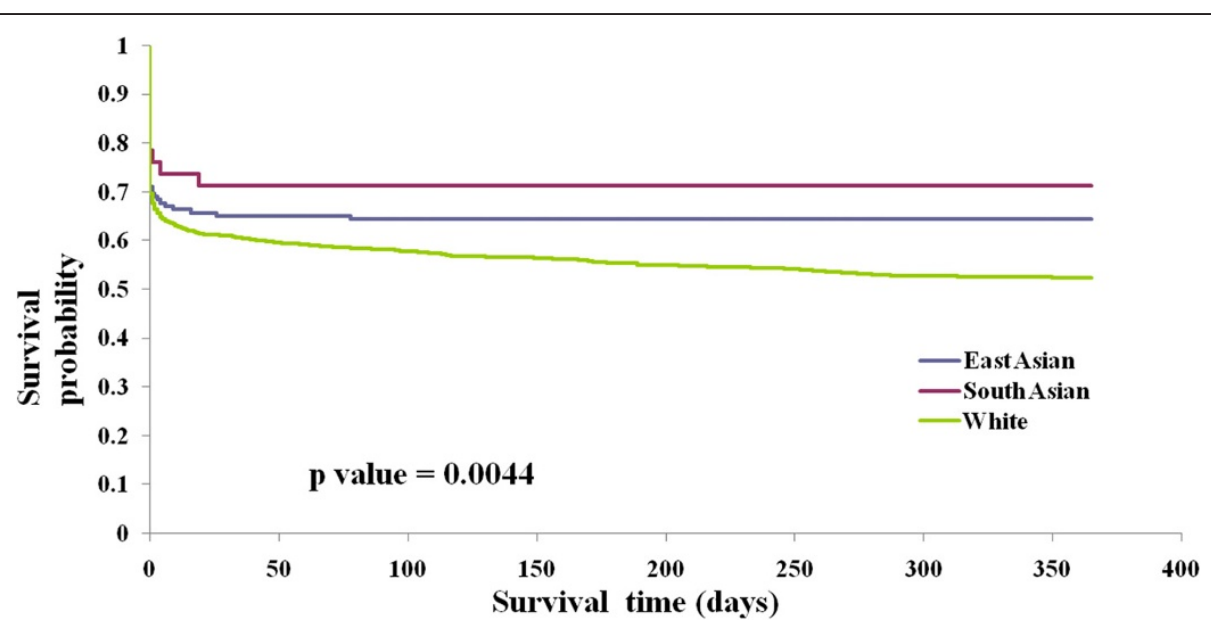

Figure 1 Kaplan Meier survival curve for one-year risk of death or recurrent stroke in ICH patients by ethnicity. 
Table 5 Adjusted outcomes according to ethnicity*

\begin{tabular}{|c|c|c|c|c|}
\hline & \multicolumn{2}{|c|}{ East Asian vs. White } & \multicolumn{2}{|c|}{ South Asian vs. White } \\
\hline & $\mathrm{HR}^{*}(95 \% \mathrm{Cl})$ & p-value & $\mathrm{HR}^{*}(95 \% \mathrm{Cl})$ & p-value \\
\hline \multicolumn{5}{|l|}{ Intracerebral hemorrhage } \\
\hline Discharged home vs. other** & $0.94(0.53$ to 1.65$)$ & 0.8 & 1.29 (0.54 to 3.1$)$ & 0.6 \\
\hline Mortality at 30 days & 1.07 (0.79 to 1.45$)$ & 0.6 & 1.3 (0.69 to 2.46$)$ & 0.4 \\
\hline Mortality at one year & 0.92 (0.69 to 1.22$)$ & 0.5 & 1.07 (0.58 to 1.96$)$ & 0.8 \\
\hline Mortality or recurrent stroke at one year & 0.89 (0.67 to 1.19$)$ & 0.4 & $0.99(0.54$ to 1.81$)$ & 0.9 \\
\hline \multicolumn{5}{|l|}{ Ischemic stroke } \\
\hline Discharged home vs. other ${ }^{* *}$ & $0.70(0.54$ to 0.90$)$ & 0.006 & $1.07(0.77$ to 1.49$)$ & 0.7 \\
\hline Mortality at 30 days & 0.81 (0.58 to 1.14$)$ & 0.2 & 0.94 (0.59 to 1.48$)$ & 0.8 \\
\hline Mortality at one year & $0.94(0.74$ to 1.2$)$ & 0.6 & $1.02(0.74$ to 1.4$)$ & 0.9 \\
\hline Mortality or recurrent stroke at one year & $0.97(0.78$ to 1.21$)$ & 0.8 & 0.91 (0.67 to 1.24$)$ & 0.6 \\
\hline
\end{tabular}

* Hazard ratios are adjusted for age, sex, area level median income, Charlson comorbidity index score, CNS score, history of atrial fibrillation, smoking status, and admission to stroke unit.

**Odds ratio among those discharged alive.

health care systems. In our study, all ethnic groups studied had significant delays in hospital arrival raising concern for a lack of recognition of stroke symptoms, failure to understand stroke as an emergency, or poor access to transportation. Despite differences in socioeconomic status, South Asian and East Asian patients were just as likely or more likely to receive appropriate emergency and in-hospital stroke management as well as secondary stroke prevention. East Asian patients were more likely admitted to the ICU. This was likely due to their higher occurrence of hemorrhagic strokes and lower levels of consciousness on admission. These findings are in contrast to two single center studies that found South Asian patients were less likely to receive lipid lowering therapy and East Asian patients were less likely to receive antiplatelet agents $[7,10]$. The lack of ethnic differences in quality of care in our study may reflect inter-regional/ inter-institutional differences or that our cohort was derived from multiple specialized stroke centers within an organized regional system of stroke care and in the context of a universal health care system.

Despite differences in baseline risk factors, short term and long term prognosis after $\mathrm{ICH}$ and ischemic stroke was generally similar among the identified ethnic groups. This extends the work by previous groups that only examined short- term outcomes in East Asian patients [8] and death certificate analyses for hemorrhagic stroke [28]. Previous studies reported conflicting findings with one study observing increased 30-day mortality in South Asian patients with ischemic stroke [29], and two studies demonstrating lower 28 day mortality in South Asian patients for all stroke [7] and lower nine-month mortality in Asian patients with ischemic stroke compared to White patients [30]. However, these studies had limited adjustment for key prognostic factors or did not separate different types of Asian patients despite significant differences in major Asian subgroups.

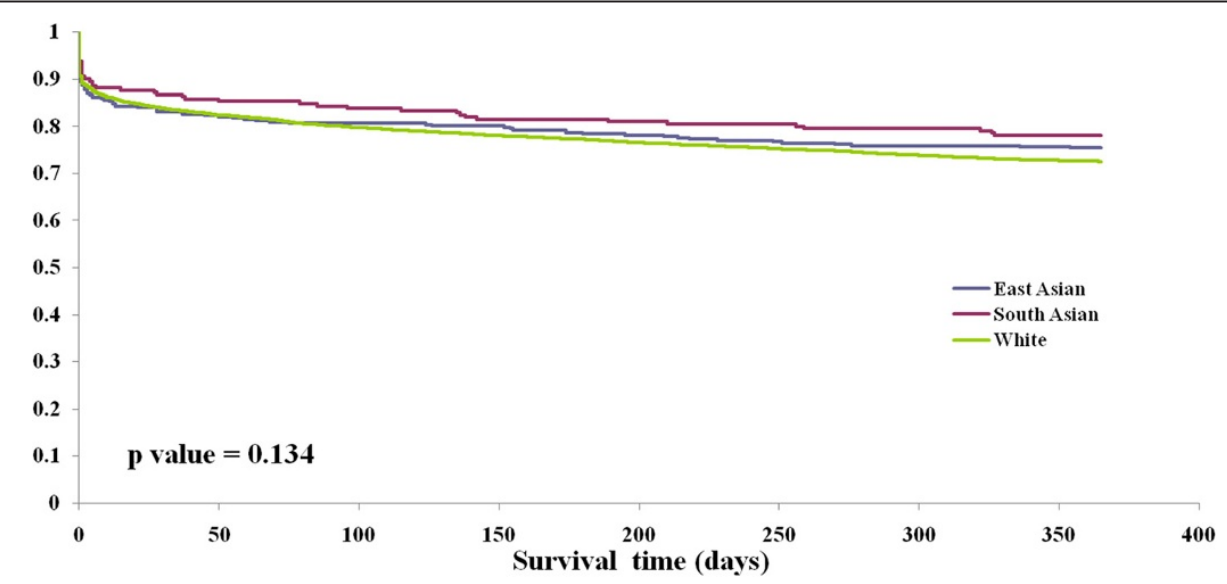

Figure 2 Kaplan Meier survival curve for one-year risk of death or recurrent stroke in ischemic stroke patients by ethnicity. 
The strengths of this study include the rigorous case ascertainment of stroke using established and uniform definitions, the multi-center, multi-ethnic cohort and an extensive adjustment for confounding prognostic factors. However, there are several limitations to be noted. First, the stroke registry only had ethnicity recorded for $60 \%$ of patients and thus, these results need to be confirmed in population-based studies. However, this analysis still represents one of the largest clinically detailed evaluations of ethnic differences in stroke care and long term prognosis in these populations. Second, our cohort comprised patients seen at urban tertiary stroke centers with neurologist and CT scanning capability therefore, our results may not be generalized to settings without these capabilities. Finally, we were unable to adjust for year of immigration or generation status. However, given that the largest Asian immigration waves in Canada were in the last 35 years [6], our cohort is likely mostly comprised of first generation immigrants.

\section{Conclusion}

Stroke is increasing dramatically in East Asian and South Asian populations globally, such that considerable efforts should be placed on stroke prevention in these groups. Our study found that stroke risk factors and stroke type differ significantly among those patients identified as East Asian, South Asian and White ethnic groups in our cohort. Future population based studies confirming these findings and evaluating the incidence of stroke subtypes among the ethnic groups are needed. Key future strategies may include improving public health programming to reduce delays in hospital arrivals for all ethnic groups, targeting East Asian patients for the prevention of hemorrhagic stroke and targeting young South Asian patients to control blood pressure and dyslipidemia. Further studies exploring the underlying mechanisms to address the higher burden of $\mathrm{ICH}$ in East Asian patients and premature ICH onset in South Asian patients are needed. Our findings of similar stroke care and prognosis between ethnic groups are reassuring but should be confirmed in centers without specialized stroke teams.

\section{Competing interests}

The authors declare that they have no conflict of interest. The institutional ethics review board of Sunnybrook Health Sciences Centre and the publications committee of the Registry of the Canadian Stroke Network approved this study.

\section{Authors' contributions}

$\mathrm{NK}, \mathrm{HQ}, \mathrm{MDH}, \mathrm{MKK}$ conceived the concept and design of the study. $\mathrm{LZ}, \mathrm{HZ}$ performed the statistical analysis. NK, HQ, AP, MDH, MKK, LZ, HZ, LP, FM, BS interpreted the results. NK, HQ, MDH, MKK, LZ, HZ, LP, AP, FM, and BS helped to draft the manuscript. All authors read and approved the final manuscript.

\section{Acknowledgments}

This study was funded by the Heart and Stroke Foundation of Canada. The Registry of the Canadian Stroke Network is funded by the Canadian Stroke Network and the Ontario Ministry of Health and Long-Term Care. The
Institute for Clinical Evaluative Sciences is supported by an operating grant from the Ontario Ministry of Health and Long-Term Care. The results and conclusions are those of the authors, and should not be attributed to any of the sponsoring or funding agencies. NAK, BRS and MKK receive support from CIHR New Investigator Awards. NAK receives support from the Michael Smith Foundation for Health Research. MKK receives support from the University Health Network Women's Health Program. HQ, MDH and FAM receive salary support from Alberta Innovates: Health Solutions. LP holds a James McGill Chair in medicine. MDH is funded by the Heart \& Stroke Foundation of Alberta, NWT, NU.

\section{Author details}

'Department of Medicine, University of British Columbia, 620 B, 1081 Burrard Street, St. Paul's Hospita, Vancouver, BC V6Z 1Y6, Canada. 'Department of Community Health Sciences, University of Calgary, Calgary, AB, Canada. ${ }^{3}$ Department of Clinical Neurosciences, University of Calgary, Calgary, AB, Canada. ${ }^{4}$ Department of Medicine, McGill University, Montreal, QC, Canada. ${ }^{5}$ Department of Medicine, University of Alberta, Edmonton, AB, Canada. ${ }^{6}$ Department of Medicine, University of Toronto, Toronto, ON, Canada. ${ }^{7}$ Institute for Clinical Evaluative Sciences, Toronto, ON, Canada.

Received: 25 May 2012 Accepted: 28 June 2013

Published: 5 July 2013

\section{References}

1. Gunarathne A, Patel JV, Gammon B, Gill PS, Hughes EA, Lip GY: Ischemic stroke in South Asians: a review of the epidemiology, pathophysiology, and ethnicity-related clinical features. Stroke 2009, 40:e415-e423.

2. Ezzati M, Rodgers A, Lopez AD, Vander Hoorn S, Murray CJL: Mortality and burden of disease attributable to individual risk factors. In Comparative quantification of health risks: global and regional burden of disease attributable to selected major risk factors. Edited by Ezzati M, Lopez AD, Rodgers A, Murray CJL. Geneva: World Health Organization; 2004:2141-2165.

3. Chen DY, Roman GC, Wu GX, Wu ZS, Yao CH, Zhang M, Hirsch RP: Stroke in China (Sino-MONICA-Beijing Study) 1984-1986. Neuroepidemiology 1992, 11:15-23.

4. Wild S, Mckeigue P: Cross sectional analysis of mortality by country of birth in England and Wales, 1970-92. BMJ 1997, 314:705-710.

5. Sheth T, Nair C, Nargundkar M, Anand S, Yusuf S: Cardiovascular and cancer mortality among Canadians of European, south Asian and Chinese origin from 1979 to 1993: an analysis of 1.2 million deaths. CMAJ 1999, 161(2):132-138

6. Statsitics Canada: 2011. Web Page. Available at: http://www.statcan.gc.ca.

7. Hsu RT, Ardron ME, Brooks W, Cherry D, Taub NA, Botha JLT: The 1996 Leicestershire community stroke \& ethnicity study: differences and similarities between South Asian and white strokes. Int J Epidemiol 1999, 28:853-858.

8. Fang J, Foo SH, Jeng JS, Yip PK, Alderman MH: Clinical characteristics of stroke among Chinese in New York City. Ethn Dis 2004, 14(3):378-383.

9. Conway DS, Lip GY: Ethnicity in relation to atrial fibrillation and stroke (the West Birmingham Stroke Project). Am J Cardiol 2003, 92(12):1476-1479.

10. Feigin V, Carter $K$, Hackett $M$, et al: Ethnic disparities in incidence of stroke subtypes: Auckland regional community stroke study, 2002-2003. Lancet Neurol 2006, 5(2):130-139.

11. Christian JB, Lapane $\mathrm{KL}$, Toppa RS, et al: Racial disparities in receipt of secondary stroke prevention agents among US nursing home residents. Stroke 2003, 34(11):2693-2697.

12. Syed NA, Khealani BA, Ali S, Hasan A, Akhtar N, Brohi H, Mozaffar T, Ahmed N, Hameed A, Baig SM, Wasay M: Ischemic stroke subtypes in Pakistan: the Aga Khan University Stroke Data Bank. J Pak Med Assoc 2003, 53:584-588.

13. Deleu D, Hamad AA, Kamram S, El Siddig A, Al Hail H, Hamdy SM: Ethnic variations in risk factor profile, pattern and recurrence of noncardioembolic ischemic stroke. Arch Med Res 2006, 37:655-662.

14. Registry of the Canadian Stroke network: 2006. https://www.rcsn.org.

15. Bamford J, Sandercock P, Dennis M, et al: Classification and natural history of clinically identifiable subtypes of cerebral infarction. Lancet 1991, 337:1521-1526.

16. Kokatailo RA, Hill MD: Coding of stroke and stroke risk factors using international classification of diseases, revisions 9 and 10. Stroke 2005, 36(8):1776-1781. 
17. Goldstein LB, Samsa GP, Matchar DB, Horner RD: Charlson Index comorbidity adjustment for ischemic stroke outcome studies. Stroke 2004, 35:1941-1945.

18. Sacco RL, Shi T, Zamanillo MC, Kargman DE: Predictors of mortality and recurrence after hospitalized cerebral infarction in an urban community: the Northern Manhattan Stroke Study. Neurology 1994, 44:626-634.

19. Collins TC, Petersen NJ, Menke TJ, et al: Short-term, intermediate-term, and long-term mortality in patients hospitalized for stroke. J Clin Epidemiol 2003, 56(1):81-87.

20. Appelros P, Nydevik I, Viitanen M: Poor outcome after first-ever stroke: predictors for death, dependency, and recurrent stroke within the first year. Stroke 2003, 34(1):122-126.

21. Côté R, Battista RN, Wolfson C, Boucher J, Adam J, Hachinski V: The Canadian Neurological Scale: validation and reliability assessment. Neurology 1989, 39(5):638-643.

22. Nguyen- Huynh M, Johnston S: Regional variation in hospitalization for stroke among Asians/Pacific Islanders in the United States: a nationwide retrospective cohort study. BMC Neurol 2005, 5:21.

23. Feigin V, Parag V, Lawes CM, Rodgers A, Suh I, Woodward M, Jamrozik K, Ueshima H, Asia Pacific Cohort Studies Collaboration: Smoking and elevated blood pressure are the most important risk factors for subarachnoid hemorrhage in the Asia-Pacific region: an overview of 26 cohorts involving 306,620 participants. Stroke 2005, 36(7):1360-1365.

24. Ueshima H, Sekikawa A, Miura K, Turin TC, Takashima N, Kita Y, Watanabe M, Kadota A, Okuda N, Kadowaki T, Nakamura Y, Okamura T: Cardiovascular disease and risk factors in Asia: a selected review. Circulation 2008, 118(25):2702-2709.

25. Banerjee S, Biram R, Chataway J, Ames D: South Asian strokes: lessons from the St Mary's stroke database. QJM 2010, 103(1):17-21.

26. De Silva DA, Woon FP, Chen C, Chang HM, Wong MC: Serum erythrocyte sedimentation rate is higher among ethnic South Asian compared to ethnic Chinese ischemic stroke patients. Is this attributable to metabolic syndrome or central obesity? J Neurol Sci 2009, 276(1-2):126-129.

27. International Consortium for Blood Pressure Genetic-Wide Association Studies: Genetic variants in novel pathways influence blood pressure and cardiovascular disease risk. Nature 2011, 478(7367):103-109.

28. Ayala C, Croft JB, Greenlund KJ, Keenan NL, Donehoo RS, Malarcher AM, Mensah GA: Sex differences in US mortality rates for stroke and stroke subtypes by race/ethnicity and age, 1995-1998. Stroke 2002, 33(5):1197-1201.

29. Gunarathne A, Patel JV, Potluri R, Gill PS, Hughes EA, Lip GY: Secular trends in the cardiovascular risk profile and mortality of stroke admissions in an inner city, multiethnic population in the United Kingdom (1997-2005). $J$ Hum Hypertens 2008, 22(1):18-23.

30. McNaughton $H$, Feigin V, Kerse N, Barber PA, Weatherall M, Bennett $D$, Carter K, Hackett M, Anderson C, Auckland Regional Community Stroke Study Group: Ethnicity and functional outcome after stroke. Stroke 2011, 42(4):960-964.

doi:10.1186/1471-2377-13-74

Cite this article as: Khan et al:: Risk factors, quality of care and prognosis in South Asian, East Asian and White patients with stroke. BMC Neurology 2013 13:74.

\section{Submit your next manuscript to BioMed Central and take full advantage of:}

- Convenient online submission

- Thorough peer review

- No space constraints or color figure charges

- Immediate publication on acceptance

- Inclusion in PubMed, CAS, Scopus and Google Scholar

- Research which is freely available for redistribution

Submit your manuscript at www.biomedcentral.com/submit 